\title{
Efficient Synthesis of 1-Amidoalkyl-2-Naphthols by One-Pot, Three-Component Reaction under Solvent-Free Conditions
}

\author{
Zahed Karimi-Jaberi, Marziyeh Jokar, and S. Zoleykha Abbasi \\ Department of Chemistry, Firoozabad Branch, Islamic Azad University, P.O. Box 74715-117, Firoozabad, Fars, Iran \\ Correspondence should be addressed to Zahed Karimi-Jaberi; zahed.karimi@yahoo.com
}

Received 7 June 2012; Revised 12 July 2012; Accepted 27 July 2012

Academic Editor: Andrea Trabocchi

Copyright (C) 2013 Zahed Karimi-Jaberi et al. This is an open access article distributed under the Creative Commons Attribution License, which permits unrestricted use, distribution, and reproduction in any medium, provided the original work is properly cited.

Two efficient and direct procedures have been developed for the preparation of 1-amidoalkyl-2-naphthols by a one-pot condensation of aldehydes, 2-naphthol, and amides in the presence of trichloroacetic acid or cobalt (II) chloride as catalyst. The reactions were carried out under solvent-free media. High yields, short reaction times, easy workup of the catalyst are advantages of these procedures.

\section{Introduction}

Multicomponent reactions (MCRs) have attracted a considerable attention in organic syntheses as they can produce the target products in a single operation without isolating the intermediates and thus reducing the reaction times and energy $[1,2]$.

Compounds bearing 1,3-amino oxygenated functional groups are ubiquitous to a variety of biologically important natural products and potent drugs including a number of nucleoside antibiotics and HIV protease inhibitors, such as ritonavir and lopinavir [3-6]. It is noteworthy that 1amidoalkyl-2-naphthols can be converted to important biologically active 1-aminomethyl-2-naphthol derivatives by amide hydrolysis reaction. The hypotensive and bradycardic effects of these compounds have been evaluated [7]. The preparation of 1-amidoalkyl-2-naphthols can be carried out by multicomponent condensation of aryl aldehydes, 2naphthol, and acetonitrile or amide in the presence of Lewis or Brønsted acid catalysts [8-20]. Although, these approaches are satisfactory for synthesis of 1-amidoalkyl 2-naphthols, the harsh reaction conditions, expensive reagents, use of toxic organic solvents, and long reaction times limit the use of these methods.

Due to extending our interest in the development of practical, safe, and environmentally friendly procedures for several important organic transformations [21-24], we now describe a simple, general, and efficient protocol for the synthesis of 1-amidoalkyl-2-naphthols by one-pot condensation reaction of 2-naphthol, aldehydes, and acetamide using catalytic amounts of trichloroacetic acid or cobalt (II) chloride under solvent-free conditions (Scheme 1).

Trichloroacetic acid and cobalt (II) chloride are readily available and inexpensive reagents and can conveniently be handled and removed from the reaction mixture. Thus, the remarkable catalytic activities together with their operational simplicity make them the most suitable catalysts for the synthesis of 1-amidoalkyl 2-naphthols. Trichloroacetic acid has been used by our group for the synthesis of dihydropyrano $[2,3-c]$ pyrazoles [21], tetrahydrobenzo $[a]$ xanthen-11-ones, and dibenzo $[a, j]$ xanthenes [22].

\section{Results and Discussion}

To optimize the reaction conditions, the reaction of 2naphthol, benzaldehyde, and acetamide was used as a model reaction. Reactions at different conditions and various molar ratios of substrates in the presence of trichloroacetic acid revealed that the best conditions were solvent-free at $120^{\circ} \mathrm{C}$ using catalytic amounts $(30 \mathrm{~mol} \%)$ of trichloroacetic acid. A slight excess of the acetamide was found to be advantageous and hence the molar ratio of 2-naphthol to acetamide was kept at $1: 1.3$. 


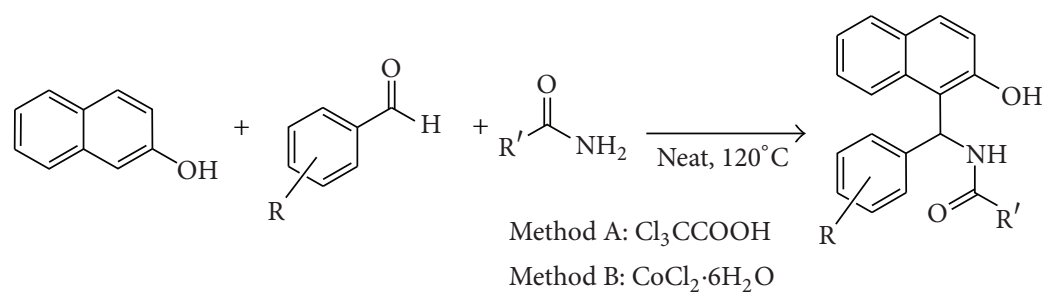

Scheme 1: Synthesis of 1-amidoalkyl 2-naphthols.

Thus, we prepared a range of 1-amidoalkyl-2-naphthols under the optimized reaction conditions: 2-naphthol ( $1 \mathrm{mmol})$, aryl aldehydes $(1 \mathrm{mmol})$, and acetamide $(1.3 \mathrm{mmol})$ in the presence of trichloroacetic acid $(0.048 \mathrm{~g}$, $30 \mathrm{~mol} \%$ ). A series of 1-amidoalkyl-2-naphthols was prepared in high to excellent yields. Several examples illustrating this novel and general method are summarized in Table 1 .

In all cases, aromatic aldehydes with substituents carrying either electron-donating or electron-withdrawing groups reacted successfully and gave the products in high yields. It was shown that the aromatic aldehydes with electronwithdrawing $\left(\mathrm{NO}_{2}, \mathrm{Cl}, \mathrm{Br}, \mathrm{F}\right)$ groups reacted faster than the aromatic aldehydes with electron-releasing $(\mathrm{Me}, \mathrm{MeO})$ group as would be expected. As reported in the literatures [8-12], the reaction of 2-naphthol with aromatic aldehydes in the presence of acid catalyst is known to give ortho-quinone methides (O-QMs). The same O-QMs, generated in situ, have been reacted with acetamide to form 1-amidoalkyl2-naphthol derivatives. A reasonable explanation for this result can be given by considering the nucleophilic addition to $\mathrm{O}-\mathrm{QM}$ intermediate favorable via conjugate addition on $\alpha, \beta$-unsaturated carbonyl group that aromatizes ring of this intermediate. The electron withdrawing groups (EWD) substituted on benzaldehyde in O-QM intermediate increase the rate of 1,4-nucleophilic addition reaction because of alkene LUMO is at lower energy in the neighboring withdrawing groups than electron-donating groups (EDG) [25]. The reactions of aliphatic aldehydes (Table 1, entry 24) instead of aromatic aldehydes would fail to give the desired products as well as the known catalysts, such as montmorillonite K10 [8], $\mathrm{K}_{5} \mathrm{CoW}_{12} \mathrm{O}_{40} \cdot 3 \mathrm{H}_{2} \mathrm{O}$ [11], and $\mathrm{Fe}\left(\mathrm{HSO}_{4}\right)_{3}$ [12].

The reaction can also proceed with different amides (acryl amide or benzamide) instead of acetamide (Table 1, entries 14-23). In all these cases, the corresponding 1-amidoalkyl-2naphthols were obtained in good yields at $120^{\circ} \mathrm{C}$ without formation of any side products such as dibenzoxanthenes, which are normally observed under the influence of strong acids. It is important to note that the synthesis of 1-amidoalkyl-2naphthols could not be achieved in the absence of catalyst $\left(\mathrm{Cl}_{3} \mathrm{CCOOH}\right)$.

Under the same conditions (solvent free at $120^{\circ} \mathrm{C}$ ), we have used cobalt (II) chloride instead of trichloroacetic acid as a catalyst. Having established the reaction conditions, various 1-amidoalkyl-2-naphthols were synthesized in excellent yields by the reaction of different aromatic aldehydes with 2-naphthol and acetamide (Table 1). In all cases 1-amidoalkyl-2-naphthols were the sole product and no by-product was observed. The reaction of aromatic aldehydes with 2-naphthol and different amides including acryl amide and benzamide under similar reaction conditions also provided the corresponding 1-amidoalkyl-2-naphthols in high yields (Table 1).

The proposed mechanism for the trichloroacetic acid catalyzed preparation of 1-amidoalkyl-2-naphthols from the reaction of 2-naphthol, aromatic aldehydes, and amides is shown in Scheme 2.

All products are known and were identified by IR and NMR spectral analysis and the results were confirmed by comparison with those available in the literature. Table 2 compares the features of the previously reported procedures with those of the present methodology for the synthesis of $\mathrm{N}$ [Phenyl-(2-hydroxy-naphthalen-1-yl)-methyl]-acetamide.

\section{Conclusion}

In conclusion, we have developed very simple and efficient methods for the high-yielding synthesis of 1-amidoalkyl2-naphthols by one-pot three-component coupling of 2naphthol, various aromatic aldehydes, and amides using trichloroacetic acid or cobalt (II) chloride as catalyst. These methods offer some advantages in terms of simplicity of performance, low reaction times, solvent-free condition, and low cost, and it follows along the line of green chemistry. The catalyst is readily available and inexpensive and can conveniently be handled and removed from the reaction mixture.

\section{Experimental}

Products were characterized by comparison of their physical and spectral data with those of authentic samples. All yields refer to isolated products after recrystallization. IR and NMR spectra were recorded on Perkin Elmer 781 and Bruker DPX500 machines. The progress of the reactions was monitored by TLC.

4.1. Typical Procedure for the Preparation of 1-Amidoalkyl2-Naphthols Using Trichloroacetic Acid (Method A). A mixture of 2-naphthol ( $1 \mathrm{mmol})$, aldehyde $(1 \mathrm{mmol})$, amide $(1.3 \mathrm{mmol})$, and $\mathrm{CCl}_{3} \mathrm{COOH}(0.048 \mathrm{~g}, 30 \mathrm{~mol} \%)$ was stirred at $120^{\circ} \mathrm{C}$ for the appropriate time indicated in Table 1 . The 
TABLE 1: Synthesis of 1-aminomethyl 2-naphthols.

\begin{tabular}{|c|c|c|c|c|c|c|c|c|}
\hline \multirow{2}{*}{ Entry } & \multirow{2}{*}{$\mathrm{R}$} & \multirow{2}{*}{$\mathrm{R}^{\prime}$} & \multicolumn{2}{|c|}{ Method A } & \multicolumn{2}{|c|}{ Method B } & \multirow[t]{2}{*}{ m.p. $\left({ }^{\circ} \mathrm{C}\right)$} & \multirow[t]{2}{*}{ [Ref.] } \\
\hline & & & Time (min) & Yield (\%) & Time (h) & Yield (\%) & & \\
\hline 1 & $\mathrm{H}$ & $\mathrm{CH}_{3}$ & 3 & 85 & 1.5 & 76 & $240-241$ & [8] \\
\hline 2 & $4-\mathrm{NO}_{2}$ & $\mathrm{CH}_{3}$ & 3 & 93 & 2 & 79 & $229-232$ & [8] \\
\hline 3 & $4-\mathrm{F}$ & $\mathrm{CH}_{3}$ & 10 & 82 & 1.5 & 68 & $224-226$ & [8] \\
\hline 4 & $2-\mathrm{NO}_{2}$ & $\mathrm{CH}_{3}$ & 15 & 95 & 1 & 83 & $217-220$ & [14] \\
\hline 5 & $2,4-\mathrm{Cl}_{2}$ & $\mathrm{CH}_{3}$ & 12 & 93 & 3 & 88 & $212-215$ & [8] \\
\hline 6 & $2,6-\mathrm{Cl}_{2}$ & $\mathrm{CH}_{3}$ & 4 & 95 & 3 & 79 & $228-230$ & {$[14]$} \\
\hline 7 & $2-\mathrm{Cl}$ & $\mathrm{CH}_{3}$ & 11 & 88 & 1.5 & 78 & 208-209 & {$[14]$} \\
\hline 8 & 2-Cl-6-F & $\mathrm{CH}_{3}$ & 4 & 91 & 1 & 90 & $225-227$ & {$[14]$} \\
\hline 9 & $4-\mathrm{Br}$ & $\mathrm{CH}_{3}$ & 4 & 95 & 2 & 83 & $235-238$ & {$[15]$} \\
\hline 10 & $3-\mathrm{NO}_{2}$ & $\mathrm{CH}_{3}$ & 3 & 95 & 1.5 & 89 & $241-243$ & {$[12]$} \\
\hline 11 & $4-\mathrm{Cl}$ & $\mathrm{CH}_{3}$ & 7 & 88 & 2 & 88 & $235-238$ & {$[14]$} \\
\hline 12 & 4-Me & $\mathrm{CH}_{3}$ & 10 & 89 & 1.5 & 78 & $219-221$ & {$[16]$} \\
\hline 13 & 3-OMe & $\mathrm{CH}_{3}$ & 2 & 87 & 2.5 & 70 & $236-238$ & [8] \\
\hline 14 & $\mathrm{H}$ & $\mathrm{CH}_{2}=\mathrm{CH}$ & 1 & 98 & 1.5 & 90 & $249-250$ & {$[10]$} \\
\hline 15 & $3-\mathrm{NO}_{2}$ & $\mathrm{CH}_{2}=\mathrm{CH}$ & 1 & 97 & 2 & 96 & $257-259$ & {$[10]$} \\
\hline 16 & $4-\mathrm{NO}_{2}$ & $\mathrm{CH}_{2}=\mathrm{CH}$ & 10 & 85 & 1.5 & 89 & $218-220$ & {$[18]$} \\
\hline 17 & $\mathrm{H}$ & $\mathrm{C}_{6} \mathrm{H}_{5}$ & 1 & 99 & 1 & 85 & $234-236$ & {$[15]$} \\
\hline 18 & $4-\mathrm{NO}_{2}$ & $\mathrm{C}_{6} \mathrm{H}_{5}$ & 7 & 93 & 1 & 90 & $238-240$ & {$[17]$} \\
\hline 19 & $3-\mathrm{NO}_{2}$ & $\mathrm{C}_{6} \mathrm{H}_{5}$ & 21 & 99 & 1 & 90 & $241-243$ & {$[14]$} \\
\hline 20 & $2-\mathrm{NO}_{2}$ & $\mathrm{C}_{6} \mathrm{H}_{5}$ & 1 & 91 & 1 & 90 & $266-267$ & {$[14]$} \\
\hline 21 & 3-OMe & $\mathrm{C}_{6} \mathrm{H}_{5}$ & 1 & 99 & 1 & 80 & $217-220$ & {$[11]$} \\
\hline 22 & $2,4-\mathrm{Cl}_{2}$ & $\mathrm{C}_{6} \mathrm{H}_{5}$ & 1 & 98 & 1 & 85 & $262-263$ & {$[14]$} \\
\hline 23 & $2-\mathrm{Cl}$ & $\mathrm{C}_{6} \mathrm{H}_{5}$ & 1 & 97 & 1 & 85 & $285-286$ & {$[14]$} \\
\hline 24 & Propionaldehyde & $\mathrm{CH}_{3}$ & 67 & Trace & - & - & - & \\
\hline
\end{tabular}

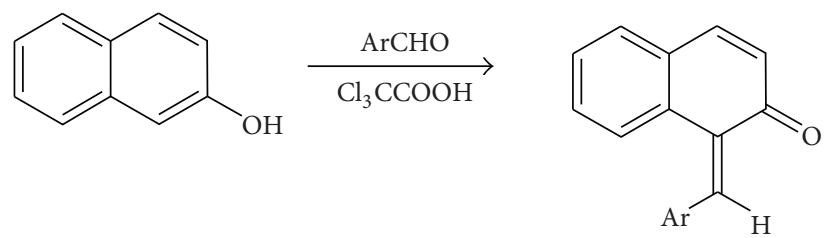<smiles>[R]C(=O)NC([Al])c1c(O)ccc2ccccc12</smiles><smiles>[R]O[Na]</smiles>

Scheme 2: Proposed mechanism.

progress of reactions was monitored by TLC (ethyl acetate/ $n$ hexane $=1 / 4)$. After completion of the reaction, a solid was obtained. It was washed with water and purified by recrystalization from ethanol to afford pure products.

4.2. Typical Procedure for the Preparation of 1-Amidoalkyl2-Naphthols Using Cobalt(II) Chloride (Method B). A mixture of 2-naphthol ( $1 \mathrm{mmol})$, aldehyde ( $1 \mathrm{mmol})$, amide $(1.3 \mathrm{mmol})$, and $\mathrm{CoCl}_{2} \cdot 6 \mathrm{H}_{2} \mathrm{O}(0.06 \mathrm{~g})$ was stirred at $120^{\circ} \mathrm{C}$ for the appropriate time indicated in Table 1. The progress of reactions was monitored by TLC. After completion of the reaction, a solid was obtained. It was washed with water and purified by recrystalization from ethanol to afford pure products. 
TABLE 2: Comparison of efficiency of various catalysts in the synthesis of 1-amidoalkyl-2-naphthols ${ }^{\mathrm{a}}$.

\begin{tabular}{lccc}
\hline Conditions & Time $(\mathrm{h})$ & Yield (\%) & Reference \\
\hline $\mathrm{Ce}\left(\mathrm{SO}_{4}\right)_{2}, \mathrm{CH}_{3} \mathrm{CN}$, reflux & 36 & 72 & {$[9]$} \\
$\mathrm{Fe}\left(\mathrm{HSO}_{4}\right)_{3}, 85^{\circ} \mathrm{C}$ & 20 & 56 & {$[12]$} \\
$\mathrm{K}_{5} \mathrm{CoW}_{12} \mathrm{O}_{40} \cdot 3 \mathrm{H}_{2} \mathrm{O}$ & 2 & 90 & {$[11]$} \\
$\mathrm{I}_{2}, 125^{\circ} \mathrm{C}$ & 4.5 & 87 & {$[10]$} \\
$\mathrm{K}-10$ clay, $125^{\circ} \mathrm{C}$ & 1.5 & 89 & {$[8]$} \\
$\mathrm{Cl}_{3} \mathrm{CCOOH}, 120^{\circ} \mathrm{C}$ & $3 \mathrm{~min}$ & 85 & This work \\
\hline
\end{tabular}

${ }^{\mathrm{a}}$ Times and yields refer to the reaction of benzaldehyde, 2-naphthol, and acetamide.

Spectral Data for Selected Products:

$\mathrm{N}$-[3-Nitrophenyl-(2-hydroxy-naphthalen-1-yl)-methyl]acetamide (Table 1, entry 10): $1 \mathrm{H}$ NMR $(500 \mathrm{MHz}, \mathrm{DMSO}-$ d6): $\delta=10.13(\mathrm{~s}, 1 \mathrm{H}), 8.62(\mathrm{~d}, 1 \mathrm{H}, \mathrm{J}=8.1 \mathrm{~Hz}), 8.05-8.001$ $(\mathrm{m}, 2 \mathrm{H}), 7.83-7.78(\mathrm{~m}, 3 \mathrm{H}), 7.56-7.40(\mathrm{~m}, 2 \mathrm{H}), 7.30-7.25$ (m, 1H), 7.19-7.15 (m, 3H), $2.01(\mathrm{~s}, 3 \mathrm{H})$.

$N$-[4-Chlorophenyl-(2-hydroxy-naphthalen-1-yl)methyl]acetamide (Table 1, entry 11): $1 \mathrm{H}$ NMR $(500 \mathrm{MHz}, \mathrm{DMSO}-$ d6): $\delta=9.84$ (brs, $1 \mathrm{H}), 8.12(\mathrm{~d}, \mathrm{~J}=8.2 \mathrm{~Hz}, 1 \mathrm{H}), 7.75(\mathrm{~d}, \mathrm{~J}=$ $8.3 \mathrm{~Hz}, 1 \mathrm{H}), 7.65-7.68$ (m, 2H), 7.08-7.46 (m, 8H), 2.08 (s, $3 \mathrm{H})$.

N-[4-Nitrophenyl-(2-hydroxy-naphthalen-1-yl)-methyl]acrylamide (Table 1, entry 16): $1 \mathrm{H}$ NMR $(500 \mathrm{MHz}, \mathrm{DMSO}-$ d6): $\delta=9.61(1 \mathrm{H}$, br. s), $8.22(1 \mathrm{H}, \mathrm{d} \mathrm{J}=8.0 \mathrm{~Hz}), 8.01(1 \mathrm{H}, \mathrm{d}$, $\mathrm{J}=8.0 \mathrm{~Hz}), 7.78-7.62(2 \mathrm{H}, \mathrm{m}), 7.33-7.22(2 \mathrm{H}, \mathrm{m}), 7.24-6.90$ $(6 \mathrm{H}, \mathrm{m}), 6.26(1 \mathrm{H}, \mathrm{d}, \mathrm{J}=12.0 \mathrm{~Hz}), 6.24(1 \mathrm{H}, \mathrm{d}, \mathrm{J}=10.0 \mathrm{~Hz})$, $5.61(1 \mathrm{H}, \mathrm{dd}, \mathrm{J}=12.0,10.0 \mathrm{~Hz})$.

$\mathrm{N}$-[3-Nitrophenyl-(2-hydroxy-naphthalen-1-yl)-methyl]benzamide (Table 1, entry 19): 1H NMR (500 MHz, DMSO$\mathrm{d} 6): \delta=10.30(\mathrm{~s}, 1 \mathrm{H}), 8.10-7.85(\mathrm{~m}, 4 \mathrm{H}), 7.65-6.95(\mathrm{~m}$, $11 \mathrm{H}), 6.55$ (br. s, $1 \mathrm{H}), 6.15$ (br. s, $1 \mathrm{H}$ ).

\section{References}

[1] A. Shaabani, A. Maleki, A. H. Rezayan, and A. Sarvary, "Recent progress of isocyanide-based multicomponent reactions in Iran," Molecular Diversity, vol. 15, no. 1, pp. 41-68, 2011.

[2] M. J. Climent, A. Corma, and S. Iborra, "Homogeneous and heterogeneous catalysts for multicomponent reactions," RSC Advances, vol. 2, no. 1, pp. 16-58, 2012.

[3] D. Seebach and J. L. Matthews, " $\beta$-peptides: a surprise at every turn,” Chemical Communications, no. 21, pp. 2015-2022, 1997.

[4] Y. F. Wang, T. Izawa, S. Kobayashi, and M. Ohno, "Stereocontrolled synthesis of (+)-negamycin from an acyclic homoallylamine by 1,3-asymmetric induction," Journal of the American Chemical Society, vol. 104, no. 23, pp. 6465-6466, 1982.

[5] S. Knapp, "Synthesis of complex nucleoside antibiotics," Chemical Reviews, vol. 95, no. 6, pp. 1859-1876, 1995.

[6] E. Juaristi, Enantioselective Synthesis of $\beta$-Amino Acids, John Wiley \& Sons, New York, NY, USA, 1997.

[7] A. Y. Shen, C. T. Tsai, and C. L. Chen, "Synthesis and cardiovascular evaluation of N-substituted 1- aminomethyl-2naphthols," European Journal of Medicinal Chemistry, vol. 34, no. 10 , pp. $877-882,1999$.
[8] S. Kantevari, S. V. N. Vuppalapati, and L. Nagarapu, "Montmorillonite K10 catalyzed efficient synthesis of amidoalkyl naphthols under solvent free conditions," Catalysis Communications, vol. 8, no. 11, pp. 1857-1862, 2007.

[9] N. P. Selvam and P. T. Perumal, "A new synthesis of acetamido phenols promoted by $\mathrm{Ce}\left(\mathrm{SO}_{4}\right)_{2}$," Tetrahedron Letters, vol. 47, no. 42, pp. 7481-7483, 2006.

[10] B. Das, K. Laxminarayana, B. Ravikanth, and B. R. Rao, "Iodine catalyzed preparation of amidoalkyl naphthols in solution and under solvent-free conditions," Journal of Molecular Catalysis A, vol. 261, no. 2, pp. 180-183, 2007.

[11] L. Nagarapu, M. Baseeruddin, S. Apuri, and S. Kantevari, "Potassium dodecatungstocobaltate trihydrate $\left(\mathrm{K}_{5} \mathrm{CoW}_{12} \mathrm{O}_{40}\right.$. $3 \mathrm{H}_{2} \mathrm{O}$ ): a mild and efficient reusable catalyst for the synthesis of amidoalkyl naphthols in solution and under solvent-free conditions," Catalysis Communications, vol. 8, no. 11, pp. 1729-1734, 2007.

[12] H. R. Shaterian, H. Yarahmadi, and M. Ghashang, "An efficient, simple and expedition synthesis of 1-amidoalkyl-2-naphthols as "drug like" molecules for biological screening," Bioorganic and Medicinal Chemistry Letters, vol. 18, no. 2, pp. 788-792, 2008.

[13] G. H. Mahdavinia, M. A. Bigdeli, and M. M. Heravi, "Silica supported perchloric acid $\left(\mathrm{HClO}_{4}-\mathrm{SiO}_{2}\right)$ : a mild, reusable and highly efficient heterogeneous catalyst for the synthesis of amidoalkyl naphthols," Chinese Chemical Letters, vol. 19, no. 10, pp. 1171-1174, 2008.

[14] G. C. Nandi, S. Samai, R. Kumar, and M. S. Singh, "Atomefficient and environment-friendly multicomponent synthesis of amidoalkyl naphthols catalyzed by $\mathrm{P}_{2} \mathrm{O}_{5}$," Tetrahedron Letters, vol. 50, no. 51, pp. 7220-7222, 2009.

[15] A. R. Hajipour, Y. Ghayeb, N. Sheikhan, and A. E. Ruoho, "Brønsted acidic ionic liquid as an efficient and reusable catalyst for one-pot synthesis of 1-amidoalkyl 2-naphthols under solvent-free conditions," Tetrahedron Letters, vol. 50, no. 40, pp. 5649-5651, 2009.

[16] M. M. Heravi, N. Tavakoli-Hoseini, and F. F. Bamoharram, "Brønsted acidic ionic liquids as efficient catalysts for the synthesis of amidoalkyl naphthols," Synthetic Communications, vol. 41, no. 2, pp. 298-306, 2011.

[17] S. A. M. K. Ansari, J. N. Sangshetti, N. D. Kokare, P. S. Wakte, and D. B. Shinde, "Oxalic acid catalyzed solvent-free synthesis of $\alpha$-amidoalkyl- $\beta$ - naphthols," Indian Journal of Chemical Technology, vol. 17, no. 1, pp. 71-73, 2010.

[18] J. Luo and Q. Zhang, "A one-pot multicomponent reaction for synthesis of 1-amidoalkyl-2-naphthols catalyzed by PEG-based dicationic acidic ionic liquids under solvent-free conditions," Monatshefte fur Chemie, vol. 142, pp. 923-930, 2011.

[19] Q. Zhang, J. Luo, and Y. Wei, "A silica gel supported dual acidic ionic liquid: an efficient and recyclable heterogeneous catalyst for the one-pot synthesis of amidoalkyl naphthols," Green Chemistry, vol. 12, no. 12, pp. 2246-2254, 2010.

[20] D. A. Kotadia and S. S. Soni, "Silica gel supported $-\mathrm{SO}_{3} \mathrm{H}$ functionalised benzimidazolium based ionic liquid as a mild and effective catalyst for rapid synthesis of 1-amidoalkyl naphthols," Journal of Molecular Catalysis A, vol. 353-354, pp. 44-49, 2012.

[21] Z. Karimi-Jaberi and M. M. ReyazoShams, "Trichloroacetic acid as a solid heterogeneous catalyst for the rapid synthesis of dihydropyrano[2,3-c]pyrazoles under solvent-free conditions," Heterocyclic Communications, vol. 17, no. 5-6, pp. 177-179, 2011. 
[22] Z. Karimi-Jaberi, S. Z. Abbasi, B. Pooladian, and M. Jokar, "Efficient, one-pot synthesis of tetrahydrobenzo[a]xanthen-11ones and dibenzo[a,j]xanthenes using trichloroacetic acid as a solid heterogeneous catalyst under solvent-free conditions," $E$ Journal of Chemistry, vol. 8, no. 4, pp. 1895-1899, 2011.

[23] Z. Karimi-Jaberi and B. Pooladian, "A facile synthesis of new 2-amino-4 h -pyran-3-carbonitriles by a one-pot reaction of $\alpha, \alpha^{\prime}$-Bis(arylidene) cycloalkanones and malononitrile in the presence of $\mathrm{K}_{2} \mathrm{CO}_{3}$," The Scientific World Journal, vol. 2012, Article ID 208796, 5 pages, 2012.

[24] Z. Karimi-Jaberi and B. Pooladian, "A facile synthesis of $\alpha, \alpha^{\prime}$ bis(substituted benzylidene) cycloalkanones catalyzed by $\mathrm{p}$ TSA under solvent-free conditions," Green Chemistry Letters and Reviews, vol. 5, no. 2, pp. 187-193, 2012.

[25] E. V. Anslyn and D. A. Dougherty, Modern Physical Organic Chemistry, University Science Books, Sausalito, Calif, USA, 2006. 

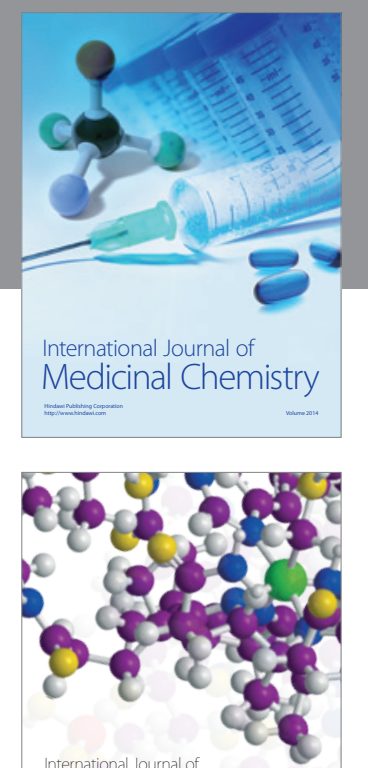

\section{Carbohydrate} Chemistry

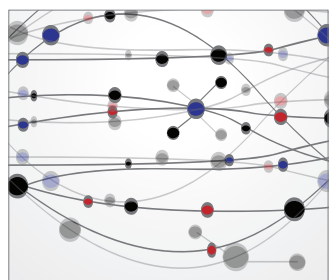

The Scientific World Journal
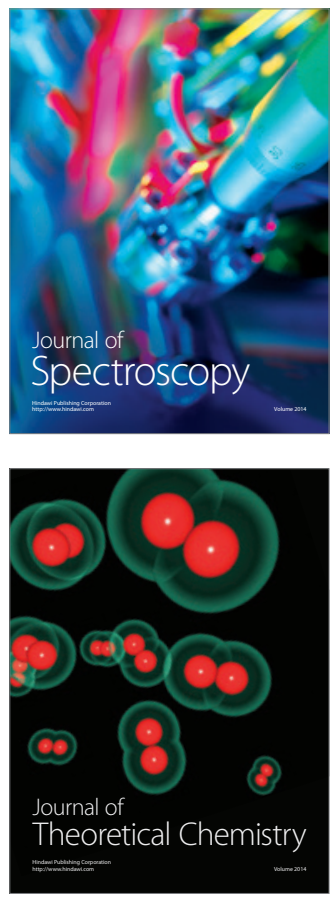
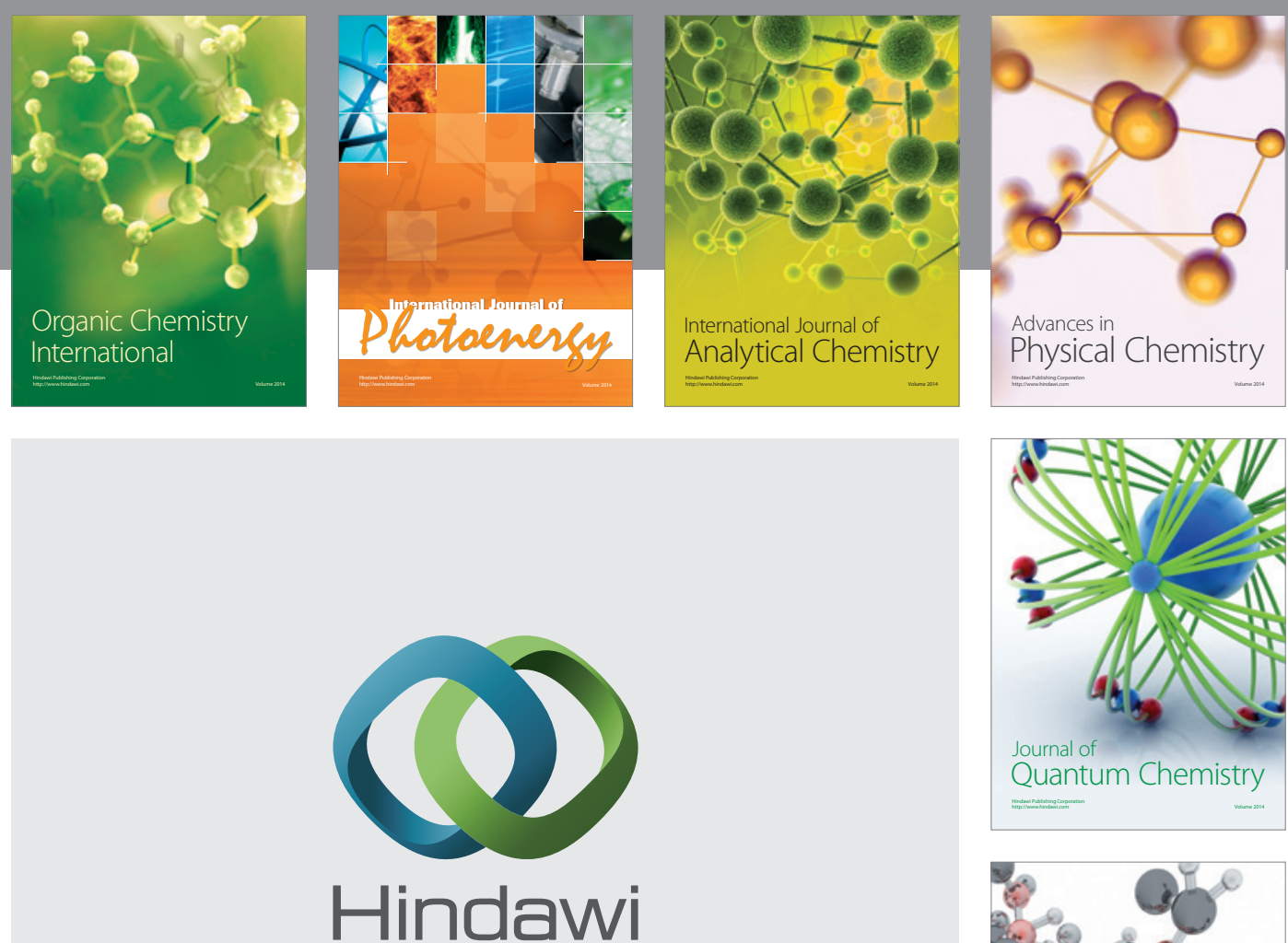

Submit your manuscripts at

http://www.hindawi.com

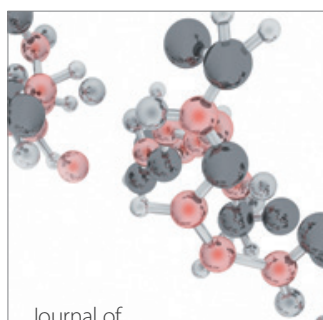

Analytical Methods

in Chemistry

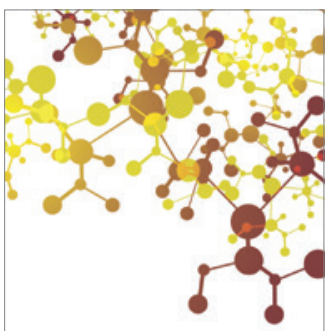

Journal of

Applied Chemistry

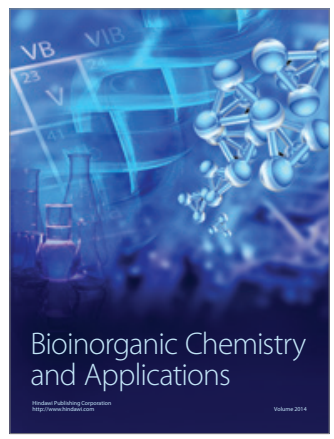

Inorganic Chemistry
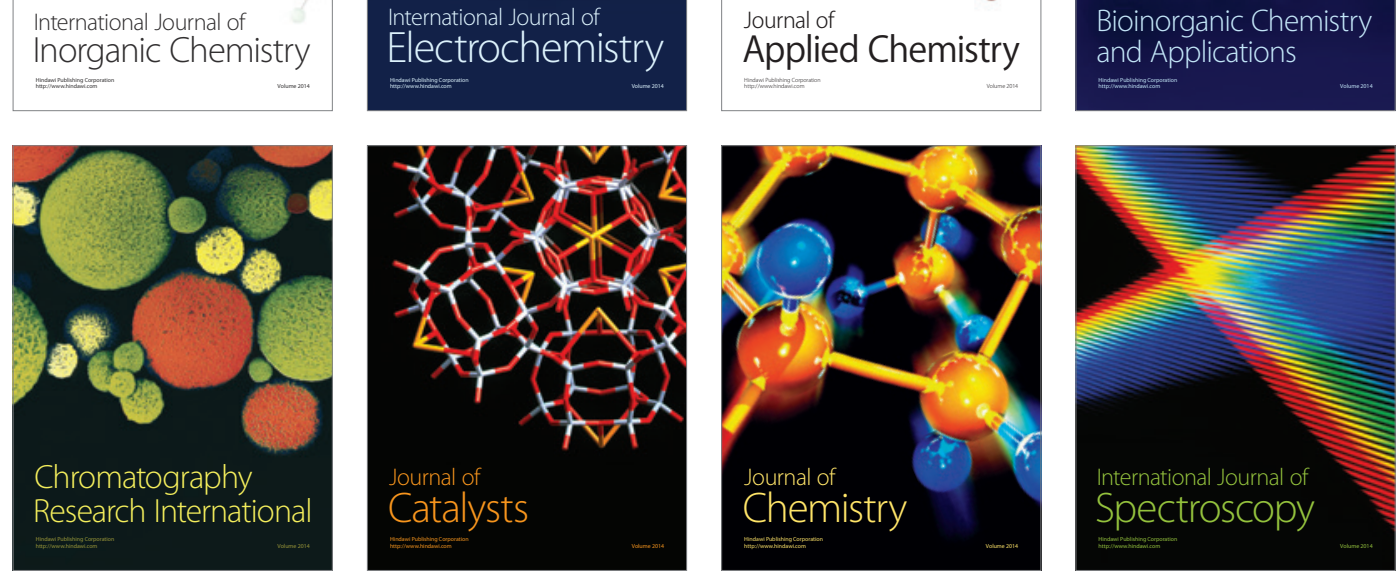